\title{
Bridging the skills gap in Zimbabwe
}

\author{
Arthur Sithole \\ Courseware Development Centre \\ P. O. Box CY1912 \\ Causeway, Harare \\ Zimbabwe \\ Tele+2634756746 \\ E-mail:asithole@zwe.toolnet.org
}

\begin{abstract}
The Zimbabwe education and training system, as is the case in any other emerging or developing nation, is experiencing problems and challenges resulting from changes in external factors such as technology, society's values and work structures. There is a need for justifications and mechanisms to build sustainable local capacities for the provision of an effective and efficient education and training system. An outline of core competencies and key qualifications required by the Zimbabwe Information Technology (IT) industry in order to empower individuals and organizations to realize their full potential is an essential ingredient for Zimbabwe's successful use of IT.
\end{abstract}

\section{Keywords}

Capacity building, competencies, skills, developing countries, national policies, professional development

\section{INTRODUCTION}

The scenario under which we are operating in Zimbabwe needs to be clearly articulated to ensure an understanding by the key stakeholders in education and training before we can discuss skills needs. There is:

- a call to empower industry and communities;

- a call for efficiency at higher levels;

- a call for outward-looking trade policies;

Capacity Building for IT in Education in Developing Countries

G. Marshall \& M. Ruohonen (Eds.)

(1) 1998 IFIP. Published by Chapman \& Hall 
- a call for private sector initiatives to lead the economic development of the nation with government as a facilitator;

- increased pressure to promote indigenous efforts in the economic development of the country;

- diminishing resource provision for training by government, donors and the private sector;

- increased rate of change of technologies (locally and abroad);

- increased unemployment in the country (school leavers, retrenchers, retired personnel, etc.);

- increasing deaths as a result of the AIDS epidemic and other ailments;

- a critical shortage of skilled people in certain sectors of our economy, e.g. engineers;

- inefficient and ineffective utilization and misallocation of certain resources within education and training, i.e. personnel, equipment, software;

- increased changes in society's value systems;

- increased changes of work structures;

- inadequate training materials and resources for schools;

- $\quad$ placement of graduates in the wrong jobs;

- insufficient monitoring of graduates' progress and how they develop in the work environment;

- increased training costs difficult to justify over a short period of time;

- increased shifting of profiles or key qualifications on the job market, especially of our trainers, institutional leadership and support personnel, etc.

It is within the purview of the above stated problems, challenges and trends that I wish to discuss the need, justification and mechanisms to build sustainable local capacities through use of IT for the provision of an efficient and effective education system.

A discussion of capacity building for IT in developing countries provides a steppingstone for a discussion of our nation's truly becoming an Information Society.

\section{DEFINITION OF KEY TERMS}

In the context of this paper, 'policy' means a general guideline for decisionmaking; 'guidelines' could include standards, procedures and regulations; a 'procedure' is a detailed set of instructions that occur often or regularly, and 'regulations' are statements that specific action must or must not be taken in a given situation. Similarly, 'skills' refer to technological, methodological and personal/social competencies.

In all fields of working life the dynamic changes presented earlier, have meant that skills once acquired will no longer last a lifetime and will age if not constantly updated to keep abreast of current developments. In other words, lifelong learning replaces longlife learning. A skill also could mean proficiency, mastery, ability or capacity. 
'NAMACO' stands for the National Manpower Advisory Council - a private body set up by act of Parliament to advise the Ministry of Higher Education and Technology on matters pertaining to education and training policy at a national level, i.e. occupational standards, accreditation, examinations, funding, curriculum quality and relevance, qualification frameworks, and access and management of the training processes. It is NAMACO's purpose to ensure the local skills base is strengthened, which will contribute to the increase in productivity, efficiency, effectiveness and competitiveness of our economy's formal and informal sectors.

Information Technology in education must be guided by an agreed-upon policy which outlines the purpose, aims and objectives of the education and training system of a nation. Such a policy could define prioritization criteria for education applications to be automated, technology acquisition, and maintenance and replacement procedures. It could also define security aspects, including use management and funding mechanisms for technologies in education. Responsible authorities and penalties could also be highlighted in such a document.

Zimbabwe has no official documented national Information Technology in education policy. The 'policy' currently guiding IT in education in Zimbabwe reacts to the needs now, and has a few mechanisms in place to predict and prepare for future IT- related needs for the country's education and training. Regarding IT use in education, several areas could be considered as important aspects of policy formulation and implementation.

Facilitate strategic planning, policy formulation and decision-making A computer-based human resources information system has been proposed at NAMACO congresses. The existing systems haven't been very reliable and thus need capacity building. A labour market information system should be a high priority to facilitate planning based on fact, according to NAMACO.

\section{Facilitate research}

Our universities and colleges are being encouraged to use local industry problems as a source for projects. I cannot comment on the degree of achievement since those data are not readily accessible.

\section{Stimulate efficient and effective IT training resource management}

There is need to identify, allocate and use resources in an efficient and effective manner. A deliberate policy has been communicated on the need to ensure full participation of both genders for any meaningful economic development in the country. While this is a grand objective, there still exist cultural barriers which will take some time before they give way. The Affirmative Action programme in place is intended to ensure equity in student distribution for all national training institutions over a period of time. This has an effect of ensuring close to full utilization of the human resources in the country's economic activities of the future. Gender distribution is currently $51 \%$ to $49 \%$ in favour of women in Zimbabwe. An IT human resources deployment survey shows that males outnumbered females by 
$28 \%$. The retired professionals are yet another untapped source to pursue via some policy framework. Technology can also be effectively used in this area.

Ensure accessibility to information technology education

Accessibility to IT education is threatened by the rising cost of living, which in turn creates or expands cultural disadvantages (classes, dropouts, etc.), thereby increasing delinquencies. Distance education approaches are being investigated to include the use of satellite technologies. Linkages between training providers is being encouraged through the infusion of private training institutions by the Ministry of Higher Education and Technology in order that they offer nationallyrecognized programmes. Data communications can play a vital role to facilitate just-in-time learning, if exploited. There is need to ensure accessibility of education delivery material to all nationally-recognized training providers. There is also a need to control or facilitate bodies but the resources are not readily available.

\section{Facilitate the development of training materials}

The Curriculum Development Unit (CRADU) of the Ministry of Higher Education and Technology is driving the development of training materials, but due to inadequate resources, the development of syllabi, question banks, etc. has not been very satisfactory. This has contributed to a mismatch between certain curriculum and change demands. CRADU, in liaison with NAMACO, has formed curriculum development committees to facilitate in this regard. Technologies used include project management software, word processors and authoring tools.

\section{Bridge or address the critical skills shortage area}

The problem of critical skills shortages has been attributed to the rate of change of technology, and to the brain drain to other more lucrative markets such as South Africa, Botswana and other countries. A number of options are being pursued to address the problem, including foreign recruitment. However, this is a very sensitive area with high unemployment in the country such that NAMACO has proposed review of policy for foreign recruitment. An exemption system as well as revision of entry requirements and qualifications for programmes are being explored by CRADU in liaison with industry. Sectorial manpower surveys continue to be done for specific industries with the Computer Industry's Manpower Survey having been held in 1994 and already out of date in some ways. Industry trainers' placement in technical colleges is being encouraged on a part-time basis to ensure relevance of education delivery. Technology could be used here for maintenance of a database of experts.

\section{Facilitate continuous professional development of users, including trainers}

In order to keep pace with IT skill demands brought about by the fast rate of change of technologies, it is necessary that staff be trained continuously. Computerbased training and audio-based training could provide a more flexible method of keeping up-to-date, particularly with packaged software. The Computer Society of Zimbabwe (CSZ) has for the past years been running a pilot scheme called the Continuous Professional Development scheme (CPD) to address this problem. 
Some CSZ functions, workshops and seminars were allocated a number of CPD hours, and society members attaining a minimum of 15 hours per society year were recognized as continuously developing themselves. Means are being investigated to incorporate other programmes which are not necessarily CSZ functions into the scheme and make attendance compulsory. In this regard we see the computer licensing scheme as a possible option whereby training establishments accredited with us could provide the training with CSZ testing the participants.

\section{Facilitate ease of mobility, portability or progression within the IT profession}

In 1994 a Career Path Model was developed by CSZ in liaison with NAMACO and is already being used for career guidance in schools. Also strides were made in 1990 by the Higher Education Ministry through a Rationalization Programme, which came up with a vocational education policy document with a Qualification Framework. This has ensured linkage between university education opportunities and training by technical colleges, which was nonexistent at independence in 1980 (in theory). The use of word processing and graphics packages is the major functionality of IT in this area.

\section{Ensure the employability of products from the IT training institutions Industrial training has been blended into nationally-recognized training programmes. Employers are being invited to participate in the running of the programmes and NAMACO, in liaison with CSZ and CRADU, are ensuring job- related programmes are in place. Also, entrepreneurship programmes as well as increased practical content in training have been introduced to facilitated self- employment. A labour market information system could be used to monitor demand, supply and use of human resources.}

\section{Guarantee the sustainability of the IT industry's human resources} Considering the AIDS menace, the rate of change of technology and general financial inadequacies, nothing of great significance has been recorded. This is attributed to the fact that the current capacity is far from meeting the demand. Now, maybe as a survival strategy, we may have to train and employ more than the anticipated need. College enrolment has been found not to match existing capacities and needs as reported at latest NAMACO congresses. This has been confirmed in our IT Manpower survey of 1994. We estimate that there may be over 400 organizations employing IT professionals in Zimbabwe.

\section{Monitoring and evaluation}

In Zimbabwe we have a Zimbabwe Manpower Development Fund (ZIMDEF) finance committee, a NAMACO/Government watchdog committee, a CSZ training institution accreditation committee, a CSZ IT industry code of practice/codes of ethics, complaints procedures and an IT Skills Requirements Model - all tools to facilitate monitoring and evaluating education practices. Technology is used for recording, financial analysis and other monitoring functions. 
The big challenge posed to the training fraternity for capacity building are developing:

- distance education and lifelong learning tools and techniques;

- occupational analysis \& skills needs identification methodologies and tools;

- qualifications standards or framework development;

- $\quad$ staff development, i.e. trainers, etc.; Teachers are the focal point of bringing a change in the education system. Expose them to IT pedagogy, emerging new technologies and other aspects of IT;

- institution management techniques and approaches;

- curriculum development methodologies;

- policy formulation and planning methodologies ;

- research on technology, the labour market and other social trends;

- access to technology and skills for materials development and skills;

- $\quad$ access to the technology and skills for courseware delivery. The potential for IT in enhancing quality of delivery of general education at the school level has not been fully recognized. Emerging technologies such as groupware, networking and multimedia can alter the way education is delivered;

- development of cooperation or networking;

- career guidance and counseling.

5 CONCLUSION

Most countries do not have policies IT in education - i.e., few countries have formal, published official statements on the subject.

Many of the problems or challenges outlined in this discussion stem not from the absence of official policy statements or similar directives, but more from the fact that critical issues are either not being addressed or are being tackled in a halfhearted way. There is a lack of action, hence the need to concentrate more on acceptance and implementation issues. This is in line with not legally incorporating the policy items for fear of stifling innovation and creativity as changes to any legislation take long to effect.

The public need to be protected from misers; they need guidance on careers; they need to be able to access facilities for IT education and training even if it is just for familiarization. Social inequalities need to be considered in arriving at standards for sound education and training practices. There is need to sensitize education planners to the potential of IT through workshops and training programmes.

Arthur Sithole is the Chairman of the Zimbabwe National Manpower Advisory Council (NAMACO) and President of the Computer Society of Zimbabwe (CSZ). $\mathrm{He}$ is also Executive Chairman of the Courseware Development Centre (CDC) PVT Ltd, Zimbabwe and a representative in IFIP TC3 and WG 3.4. Previously he 
was the IT Field Consultant for the Eastern \& Southern African Management Institute (ESAMI). Arthur has presented papers at many local and international forums, including conferences held in Singapore, Botswana, Lesotho, Malta and South Africa - the latest of which won him the Zimbabwean prestigious Carlisle Award last year. 